\title{
Cooperativas estudantis universitárias na Bahia: desafios e
}

\section{oportunidades}

Maryelle Vanilla de Abreu Cerqueira ${ }^{1 *}$, José Raimundo Oliveira ${ }^{2}$, Myrelle dos Santos Nascimento $^{3}$, Fillipe Duarte Ribeiro ${ }^{4}$

\author{
${ }^{1}$ Universidade Estadual de Feira de \\ Santana (UEFS). Departamento de \\ Ciências Biológicas (DBio). Graduanda \\ do curso de Engenharia Agronômica \\ https://orcid.org/0000-0001-8476- \\ $\underline{6289}$ \\ 2Universidade Estadual de Feira de \\ Santana (UEFS). Departamento de \\ Ciências Sociais (DCIS) Aplicadas. \\ Programa de Pós-Graduação em \\ Planejamento Territorial (PLANTERR) \\ - Mestrado. \\ https://orcid.org/0000-0002-3646- \\ $\underline{307 X}$
}

${ }^{3}$ Universidade Estadual de Feira de Santana (UEFS). Departamento de Ciências Biológicas (DBio). Graduanda do curso de Engenharia Agronômica. https://orcid.org/0000-0003-4328$\underline{4245}$

${ }^{4}$ Universidade Estadual de Feira de Santana (UEFS). Departamento de Ciências Biológicas (DBio). Graduando do curso de Engenharia Agronômica. https://orcid.org/0000-0002-5383$\underline{1428}$

\footnotetext{
*Autor correspondente: maryellevanilla@gmail.com
}

\section{Resumo:}

Este trabalho objetiva analisar as possibilidades de implantação de Cooperativas Estudantis Universitárias da Bahia a partir da discussão sobre cooperativismo, com base em seus princípios e fundamentos. Tal tipologia organizativa pode ser formada e mantida por estudantes cooperados e surge como uma importante ferramenta, onde os estudantes têm a oportunidade de lidar com a prática dos conteúdos obtidos em sala de aula, além de desenvolverem a capacidade de atuação profissional em um diferente modelo, contribuindo assim, para um processo educativo mais amplo na formação dos associados e comunidades. A metodologia adotada nesta pesquisa tem sustentação teórica em referências da área, no estudo de documentos normativos sobre o cooperativismo, bem como em entrevistas com professores de universidades estaduais da Bahia que têm ou tiveram relação com Cooperativas. Como resultado, observou-se a relevância das cooperativas estudantis na formação profissional dos estudantes de Agronomia, além das dificuldades de seu estabelecimento no âmbito universitário, relacionando-as aos entraves culturais e acadêmicos apresentados a partir da natureza de ser das universidades, cuja dinâmica volta-se restritivamente para o empreendedorismo empresarial.

Palavras-chave: Cooperativismo. Cooperativas Estudantis. Princípios e fundamentos.
REVISTA MACAMBIRA

Instituto Federal de Educação, Ciência e Tecnologia Baiano, campus Serrinha. Estrada Vicinal de Aparecida, s/n, Bairro Aparecida, Serrinha (Ba), CEP: 48700-000, sala 01, prédio acadêmico. 


\section{University student cooperatives in Bahia: challenges and opportunities}

Maryelle Vanilla de Abreu Cerqueira ${ }^{1 *}$, José Raimundo Oliveira ${ }^{2}$, Myrelle dos Santos Nascimento ${ }^{3}$, Fillipe Duarte Ribeiro ${ }^{4}$

\author{
1 Universidade Estadual de Feira de \\ Santana (UEFS). Department of \\ Biological Sciences (DBio). \\ Undergraduate student in \\ Agronomic Engineering \\ https://orcid.org/0000-0001-8476- \\ $\underline{6289}$ \\ 2 Universidade Estadual de Feira de \\ Santana (UEFS). Department of \\ Applied Social Sciences (DCIS). \\ Postgraduate Program in Territorial \\ Planning (PLANTERR) - Master. \\ https://orcid.org/0000-0002-3646- \\ $\underline{307 X}$
}

${ }^{3}$ Universidade Estadual de Feira de Santana (UEFS). Department of Biological Sciences (DBio). Graduate student in Agronomic Engineering course.

https://orcid.org/0000-0003-4328$\underline{4245}$

${ }^{4}$ Universidade Estadual de Feira de Santana (UEFS). Department of Biological Sciences (DBio). Graduat student in Agronomic Engineering course.

https://orcid.org/0000-0002-5383$\underline{1428}$

*Corresponding author:

maryellevanilla@gmail.com

\begin{abstract}
:
This study aims to analyze the possibilities of implementing University Student Cooperatives in Bahia from the discussion of cooperatives based on its principles and foundations. Such organizational typology can be formed and maintained by cooperative students and appear as an important tool, where students have the opportunity to apply the contents learned in the classroom in a practical way, in addition to developing the capacity for professional performance in a different production model, thus contributing to a broader educational process in the training of associates and communities. The methodology adopted in this research has theoretical support in references of the area, in the study of normative documents about cooperativism, as well as in interviews with professors from state universities in Bahia that have or had relation with Cooperatives. As a result, the relevance of student cooperatives in the professional training of Agronomy students was observed, in addition to their difficulties in establishing themselves at the university level, relating them to the cultural and academic obstacles presented from the nature of being of universities, whose dynamics return to restrict itself to entrepreneurial entrepreneurship.
\end{abstract}

Keywords: Cooperativism. University Student Cooperatives. Principles and fundamentals.
MACAMBIRA JOURNAL

Federal Institute of Education, Science and Technology Baiano, campus Serrinha. Estrada Vicinal de Aparecida, s/n, Bairro Aparecida, Serrinha, Bahia, Brasil, CEP: 48700-000, sala 01, prédio acadêmico. 


\section{Introdução}

O cooperativismo pode até ter um campo teórico consolidado, porém, esse mesmo campo não responde às particularidades de cada tempo e lugar onde o cooperativismo se mostra necessário, porém as cooperativas populares autênticas expressam princípios da economia solidária que, por sua vez, segundo Singer et al. (2003a, p. 116), é um conceito amplamente utilizado em diversas partes do mundo, “com acepções variadas, mas que giram todas ao redor da ideia da solidariedade, em contraste com o individualismo competitivo que caracteriza o comportamento econômico padrão nas sociedades capitalistas". As Sociedades Cooperativas funcionam de forma diferente do modelo capitalista de produção, que prima pelo lucro. Ao contrário, as cooperativas buscam difundir uma organização mais solidária, democrática e educativa a partir dos princípios cooperativistas que rezam seus próprios documentos legais e normas internas.

Como uma vertente não comum, as cooperativas estudantis são modelos de organização socioprodutiva formadas e mantidas por estudantes cooperados, enquadrando-se no plano educacional ao objetivar melhores condições de ensino, pesquisa e extensão (RUVER, 2018). Surgem como uma importante ferramenta através da qual os estudantes têm a oportunidade de aplicação prática dos conteúdos trabalhados em sala de aula, além de desenvolverem a capacidade de atuação profissional em um diferente modelo de construção, assim contribuindo para a formação dos associados por vias do trabalho educativo coletivo, fundamentado também no princípio da educação cooperativa.

Embora a relevância do trabalho cooperativo seja reconhecida, ainda não existem cooperativas estudantis implantadas no estado da Bahia, bem como não são encontradas muitas produções para este tema a nível nacional. Dessa forma, buscamos através deste trabalho promover discussões sobre a importância das Cooperativas Estudantis Universitárias, levando em conta as dificuldades encontradas para sua implementação, assim como as oportunidades atuais, de forma a constituir uma problematização a respeito da ausência desse tipo de organização no estado.

Nesse contexto, este trabalho aponta como objetivo analisar as possibilidades de implantação de Cooperativas Estudantis Universitárias na Bahia, tendo como base uma discussão sobre os princípios e fundamentos do cooperativismo.

Para alcançar o objetivo da pesquisa, inicialmente realizamos diálogos e ações de aproximação com atores envolvidos com a temática, bem como fizemos buscas em bases de dados eletrônicas acerca do tema, além das fontes baseadas em observações acadêmicas e entrevistas a quatro docentes de duas universidades da Bahia, envolvidos com as áreas de Ciências Agrárias e Economia Solidária, no período entre outubro de 2019 e março de 2020.

A pesquisa-ação consubstancia-se em um ambiente de interlocução onde os atores implicados participam ou criam formas de ambientalizar suas relações de atuação, possibilitando a resolução dos 
problemas com conhecimentos diferenciados, articulação de saberes criando possibilidades disciplinares, inter e transdisciplinares em que, necessariamente, impulsiona as ações que, no percurso destas, possibilitam inferências e descobertas que ocorrem, não necessariamente de forma planejada, suscitando resultados positivos ao longo do processo de estudos.

A Incubadora de Iniciativas de Economia Popular e Solidária da Universidade Estadual de Feira de Santana (IEPS-UEFS), o Grupo de Estudos e Pesquisas sobre Economia Solidária e Desenvolvimento Local (GEPOSDEL-UEFS), a articulação entre cursos de agronomia, considerando corpos discentes e docente, bem como o envolvimento com as comunidades onde as práticas de cooperação são desenvolvidas possibilitaram promover todo o desenrolar e a caracterização da metodologia desta pesquisa.

Nesse sentido, a metodologia adotada nesta pesquisa reveste-se das interações e imbricações possibilitadas pela pesquisa-ação, conforme discute Thiollent (2011), com sustentação teórica em referências da área do cooperativismo e no estudo de documentos normativos sobre o tema, bem como em entrevistas com professores da Universidade Estadual de Santa Cruz - UESC e da UEFS, que têm ou tiveram alguma relação com Cooperação Estudantis. Além disso, a temática tem amparo nas discussões realizadas no transcurso da disciplina Comercialização e Economia Solidária, do curso de Agronomia alimentada pelo GEPOSDEL, base orientadora dos trabalhos da IEPS-UEFS.

Este texto divide-se em três partes, sendo que a primeira traz uma definição do que são cooperativas, seus princípios e fundamentos. A segunda parte traz o conceito ou definição de cooperativa estudantil, seu funcionamento e dificuldades encontradas para estabelecimento no ambiente universitário. Por fim, são apresentados alguns mecanismos possíveis para implementação destas cooperativas. Desta forma, além dessa introdução e das considerações finais, apresentam-se os seguintes eixos temáticos: i) Cooperativismo: conceito, princípios e práticas; ii) Cooperativas estudantis universitárias: aspectos gerais e desafios enfrentados na Bahia; iii) Oportunidades para implementação de uma cooperativa estudantil universitária na Bahia.

\section{Cooperativismo: conceito, princípios e práticas}

O cooperativismo é um movimento socioeconômico capaz de unir desenvolvimento econômico e mobilização, bem como coesão social, por via do trabalho associado. Possui referenciais fundamentados em participação democrática, solidariedade, independência e autonomia. Além disso, o sistema é consubstanciado na reunião de pessoas, nos coletivos de trabalho, e não na articulação das cotas-partes de capital apenas. Nesse sentido, as cooperativas podem ser definidas como associações de pessoas produtoras, fabricantes e consumidoras, entre outras que, reciprocamente, possuem o compromisso de 
contribuir com bens ou serviços para o exercício de uma atividade econômica e democrática, não objetivando exacerbadamente e acima de tudo as vendas e os lucros (REISDORFER, 2014).

Nesse contexto, interessa-nos muito mais compreender os mecanismos que direcionam ou reforçam o pensamento cooperativista, para uma prática social relevante do que os percalços ou desvios de princípios, que podem levar a experiências distorcidas de cooperativismo. Compreendendo que, as disfunções ocorrem muito mais por falhas das pessoas que se distanciam de práticas comunitárias éticas e democráticas, do que por defeitos atribuídos ou considerados inerentes a essa tipologia organizativa.

Corroborando com a perspectiva apresentada, Aragão (2013) afirma que o cooperativismo pode se tornar a base econômica da sociedade moderna na medida em que as unidades produtivas se orientem por princípios relacionados à democracia e à valorização do trabalho, os quais são descritos por Veiga e Fonseca (2002, p. 44), como: “Adesão voluntária e livre, Gestão democrática pelos membros, participação econômica dos membros, autonomia e independência, educação, formação e informação, Intercooperação e interesse pela comunidade".

Por sua vez, corroborando com Aragão (2013), considerando que o trabalho ou a preparação para executar o cooperativismo, que é um elemento fundamental para o processo educativo, inclusive dos jovens em fase de aprendizagem, Bocayuva (2002) nos atualiza quando afirma que:

As cooperativas geram empregos e produzem efeitos econômicos estruturantes na medida em
que se tornam empresas sustentáveis. [...] Os princípios de cooperação e interação sociocultural
que marcam o cooperativismo são atualizados por força das lógicas participativas,
comunicacionais e cooperativas, desencadeadas na crise de paradigmas organizacionais no
mundo do trabalho. Integração no território e nas redes de relacionamentos e informação, mais
ou menos formalizadas, sem as quais não existem mercados e formas de vida social. Poder de
pressão coletiva e capacidade de organizar as demandas de apoio político. São capazes de
articular o potencial humano e social como componente estratégico ou capital empresarial na
forma organizacional e nas opções técnico-produtivas. Facilitam a incorporação e o trabalho
para jovens, mulheres e idosos considerados desqualificados por outros modelos empresariais
(BOCAYUVA, 2002, p. 91).

$\mathrm{Na}$ esteira da perspectiva trazida pelos autores citados até aqui, abrigamo-nos em princípios que remontam debates e praxes educativas relevantes em diversas partes do mundo. Os primeiros princípios são fundamentados na regulamentação da primeira cooperativa formal de consumo de Rochdale, formada no ano de 1844 (PINHEIRO, 2008), referenciados até os dias atuais. Suas definições foram estabelecidas durante a realização do congresso da Aliança Cooperativa Internacional, que aconteceu no ano de 1995, em Manchester, na Inglaterra, sempre tentando manter a fidelidade ao Pioneirismo Cooperativo (CANÇADO; SOUZA; PEREIRA, 2014), conforme apresentado no Quadro 1. 
Quadro 1 - Princípios cooperativistas: limites e possibilidades.

\begin{tabular}{|c|c|c|}
\hline PRINCÍPIO & DEFINIÇÃO & LIMITES/POSSIBILIDADES \\
\hline $\begin{array}{l}1^{\circ} \text { Adesão Voluntária e } \\
\text { Livre Acesso }\end{array}$ & $\begin{array}{l}\text { As Cooperativas são } \\
\text { organizações voluntárias } \\
\text { abertas a todas as pessoas } \\
\text { aptas para usarem seus } \\
\text { serviços e estrutura. }\end{array}$ & $\begin{array}{l}\text { Ninguém pode ser obrigado a ingressar } \\
\text { em uma cooperativa nem impedido de } \\
\text { sair. Não existe um "dono" que ordena } \\
\text { ou regula entrada e saída de pessoas. }\end{array}$ \\
\hline $\begin{array}{l}2^{\circ} \text { Gestão e Controle } \\
\text { Democrático por parte dos } \\
\text { Sócios }\end{array}$ & $\begin{array}{|lrr|}\text { As } & \text { cooperativas rão } \\
\text { organizações } & \text { democráticas } \\
\text { controladas } & \text { por seus sócios. } \\
\end{array}$ & $\begin{array}{l}\text { Todos os associados têm os mesmos } \\
\text { poderes, ou seja, igual direito de } \\
\text { participação e voto. }\end{array}$ \\
\hline $\begin{array}{l}3^{\circ} \text { Participação Econômica } \\
\text { do Sócio }\end{array}$ & $\begin{array}{l}\text { Os sócios contribuem } \\
\text { equitativamente e controlam } \\
\text { democraticamente o capital } \\
\text { em cotas-partes. }\end{array}$ & $\begin{array}{l}\text { O terceiro princípio do cooperativismo } \\
\text { pode se tornar limitador quando não se } \\
\text { tem comprometimento e compreensão } \\
\text { dos valores e princípios. Pode se tornar } \\
\text { excludente pela renda. }\end{array}$ \\
\hline $\begin{array}{l}4^{\circ} \text { Autonomia e } \\
\text { Independência }\end{array}$ & $\begin{array}{l}\text { As cooperativas são } \\
\text { organizações autônomas de } \\
\text { ajuda mútua, controladas por } \\
\text { seus membros. }\end{array}$ & $\begin{array}{l}\text { Devem se desenvolver de forma que } \\
\text { fiquem independente do governo, sem } \\
\text { sofrer influências externas ou de qualquer } \\
\text { relação de poder. }\end{array}$ \\
\hline $\begin{array}{l}5^{\circ} \text { Princípio da Educação, } \\
\text { Treinamento e Informação } \\
\text { Cooperativa }\end{array}$ & $\begin{array}{l}\text { As cooperativas oferecem } \\
\text { educação e treinamento para } \\
\text { seus sócios, representantes } \\
\text { eleitos, administradores e } \\
\text { funcionários. }\end{array}$ & $\begin{array}{l}\text { Esse princípio é primordial para o } \\
\text { contínuo crescimento da cooperativa e do } \\
\text { cooperativismo como um todo. Se bem } \\
\text { utilizado, faz a diferença entre as } \\
\text { tipologias organizativas e revela-se um } \\
\text { importante elemento do processo } \\
\text { "político" educativo de trabalho. }\end{array}$ \\
\hline $\begin{array}{l}6^{\circ} \text { Princípio da Cooperação } \\
\text { Intercooperativa e } \\
\text { Integração Cooperativa }\end{array}$ & \begin{tabular}{|l|} 
As cooperativas fortalecem \\
o movimento cooperativo \\
trabalhando juntas através \\
de estruturas locais, \\
nacionais, regionais e \\
internacionais. \\
\end{tabular} & $\begin{array}{l}\text { O hábito de atuarem de forma individual } \\
\text { é um dos fatores que impedem a } \\
\text { intercooperação no noristema } \\
\text { cooperativista. Assim, as cooperativas } \\
\text { territoriais potencializam a aprendizagem } \\
\text { e o desenvolvimento local endógeno. }\end{array}$ \\
\hline $\begin{array}{l}7^{\circ} \text { Princípio da Preocupação } \\
\text { com a Comunidade }\end{array}$ & $\begin{array}{|lrr|}\text { As } & \text { cooperativas } & \text { trabalham } \\
\text { pelo } & \text { desenvolvimento } \\
\text { sustentável } & \text { de } & \text { suas } \\
\text { comunidades. } & & \end{array}$ & $\begin{array}{l}\text { Não se pode entender as cooperativas } \\
\text { isoladamente, mas sim, dentro do } \\
\text { contexto social, principalmente, local. }\end{array}$ \\
\hline
\end{tabular}

Fonte: Elaborado pelos autores, 2020. Adaptado

Base de dados: Cançado; Souza; Pereira, 2014.

O Quadro 1 apresenta o caráter organizativo e educativo de cooperativas, entre limites e possibilidades, enquanto tipologia diferenciada cuja dinâmica de condução não pode ser atribuída a um "dono", a um "chefe", pois, trata-se de uma estrutura organizativa, educativa e, necessariamente, de pessoas (e não de capital) envolvidas no trabalho coletivo. Mostra-nos também, que de nada adiantam princípios que apontam para o desenvolvimento e empoderamento coletivo e comunitário, por via da autonomia, da liberdade e da educação contínua, se esses princípios não forem praticados com bastante 
esmero e motivação social. Dada a relevância dessa tipologia para a sociedade, é de fundamental importância sua inserção também no ambiente acadêmico universitário, seja no âmbito do ensino, da pesquisa, da extensão, ou como forma de promover o diálogo entre as diversas formas de saberes.

Uma tipologia dessa natureza, quando conduzida por estudantes de graduação em uma universidade pública, deve se dar, necessariamente, em observância aos princípios aprovados no congresso de Manchester conforme nos indica Pinheiro (2008). Esse elemento, relevante por si só, quando adotado desde uma perspectiva institucional, tem a potencialidade de conduzir processos educativos, políticos e democráticos fundamentais para a formação acadêmica e de vida das pessoas, ampliando seus horizontes no sentido do reconhecimento da pluralidade de experimentos, vivências e realidades socioeconômicas que extrapolem a visão empresarial de mundo, sempre voltada para o acúmulo de capital. Possibilita-se, assim, a valorização de experiências de organização social alternativas, abertas à associação de pessoas para a produção econômica e de modos de vida diversos.

\section{Cooperativas estudantis universitárias: aspectos gerais e desafios enfrentados na Bahia}

O ambiente acadêmico universitário é local privilegiado para debates acerca de temas ligados à educação, tais como organização curricular. Dentro das discussões sobre o perfil profissional adequado ao mercado de trabalho, recebe destaque, por exemplo, o papel das empresas e consultorias juniores na formação acadêmica dos estudantes. No entanto, pouca atenção tem sido dedicada às formas de organizações alternativas, como as cooperativas. Um levantamento inicial realizado no transcurso da disciplina Comercialização e Economia Solidária, do curso de Agronomia da Universidade Estadual de Feira de Santana (UEFS), revelou que no estado da Bahia não existem cooperativas estudantis juniores, e essa informação se converteu em problema de pesquisa.

Uma cooperativa estudantil pode ser compreendida como uma atividade cooperada no ambiente educacional, visando otimizar as condições de diálogo, ensino, pesquisa e extensão dos estudantes. Além disso, oferece a oportunidade de produção e/ou comercialização dos produtos e serviços realizados, podendo ser caracterizadas como cooperativas de produção, consumo, trabalho ou outras formas (RUVER, 2018). Outro fator importante é a promoção de oportunidades de contato com os riscos inerentes por exemplo, e também, ao negócio agrícola, ou de outra natureza - uma vez que tais unidades são formadas e mantidas pelos cooperados (SANTOS, 2020).

De acordo com Cruz (2020), os estudantes podem comercializar os produtos obtidos dentro da própria comunidade acadêmica e realizar outras atividades educativas, como comércio de livros e materiais relacionados às suas áreas. Além disso, ainda podem atuar com outros projetos da universidade. 
Segundo Moureu (2020), a experiência proporcionada aos estudantes abrirá um leque maior de possibilidades de atuação no mercado de trabalho.

Salientamos, ainda, a relevância das organizações estudantis, ou coordenadas por estudantes, na perspectiva do enriquecimento da experiência acadêmica. As problemáticas enfrentadas nessas organizações podem constituir-se em rico material a ser trabalhado em sala de aula e em atividades práticas. Além disso, prestam-se ao debate político acerca da pertinência e implicações da implantação de organizações privadas dentro de instituições públicas. Até então, nossa experiência junto à UEFS permite-nos observar a existência de serviços terceirizados e negócios privados em funcionamento na instituição, embora o assunto permaneça sendo um tabu. $\mathrm{O}$ debate franco sobre o tema, lastreado em pesquisas e experiências, poderia permitir a elaboração de sínteses e, quem sabe, balizar intervenções administrativas, podendo até reorientar práticas institucionais.

A falta de discussões acadêmicas organizadas, por outro lado, favorece a naturalização de modelos hegemônicos, e obstaculiza a proposição de alternativas a práticas que são alvo de questionamento. No sentido de ilustrar a complexidade do debate, bem como a diversidade de conhecimentos e relações entre saberes que as experiências de cooperativismo podem representar para os estudantes universitários, Araújo (2016) nos apresenta que:

[...] dentro do cooperativismo brasileiro, observam-se divergentes correntes político ideológicas entre as instituições. A corrente tradicional representada pela Organização das Cooperativas Brasileiras (OCB), criada pela Lei 5764/71, e a corrente solidária, representada pelas organizações Central de Cooperativas e Empreendimentos Solidários (UNISOL Brasil); Confederação das Cooperativas de Reforma Agrária do Brasil (CONCRAB); Associação Nacional de Trabalhadores e Empresas de Autogestão (ANTEAG), (a UNISOL BRASIL ligada principalmente ao movimento sindical, a ANTEAG as empresas recuperadas para sistema de autogestão e a CONCRAB ao Movimento dos Trabalhadores Rurais Sem-Terra - MST); e União Nacional das Cooperativas da Economia Familiar e Solidária (UNICAFES), organização fundada no ano de 2005 (ARAÚJO, 2016, p. 47).

Dada a diversidade de modelos exposta, observamos que para fundar uma cooperativa, é necessária uma grande dedicação dos interessados, além de orientações interdisciplinares e espaço físico para realização das atividades. Para cooperativas estudantis agrícolas, por exemplo, é importante que haja uma boa área para cultivo, com disponibilidade hídrica, que deve ser providenciada pela universidade ou por uma comunidade parceira. Também é necessária a elaboração de um estatuto, com a participação de todos, fazendo um levantamento das necessidades jurídicas, contábeis, econômicas, dentre outras, no qual sejam instituídos os mecanismos de tomada de decisão, bem como de participação da diretoria e dos cooperados (estudantes), que deverá ser sempre de forma democrática.

Assim, inferimos que, mesmo considerando sua importância para o desenvolvimento social e acadêmico, a formação de Cooperativas Estudantis precisa superar diversos entraves, que vão desde a disponibilidade dos estudantes até o apoio da Universidade, bem como seus trâmites burocráticos, entre outras questões e até preconceitos associados ao cooperativismo popular, dos quais não trataremos aqui. 
Além disso, é possível identificar certa deficiência de estudos relacionados ao tema, que não possui um quantitativo considerável de publicações (RUVER, 2020), assim representando a falta de disponibilidade de aporte teórico.

Segundo Santos (2020), algumas dificuldades para a implementação de cooperativas estudantis são a articulação dos estudantes, a disposição destes para este tipo de empreendedorismo, a responsabilidade em arcar com os custos econômicos e desgaste físico das atividades propostas e o apoio da universidade para a gestão, além de laboratórios e liberação de áreas para atividades técnicas com disponibilidade de água e outros serviços. Devemos considerar, ainda, fatores subjetivos, ligados ao modelo de formação acadêmica e estruturas curriculares, que podem constituir-se em entraves ao engajamento dos estudantes em experiências de ensino-aprendizagem menos comuns. Mais uma vez, a nossa experiência permite-nos elencar, a título de exemplo: a pressão para cumprimento de créditos de disciplinas em tempo mínimo; currículos travados com pré-requisitos; desprestígio de atividades de campo quando comparadas às atividades de sala de aula; inseguranças ligadas ao futuro profissional, dentre outras. Todos esses fatores podem contribuir para a falta de iniciativas voltadas para a implantação de cooperativas estudantis.

No tocante às relações acadêmicas e fazeres de extensão e pesquisa estudantil, Castro (2020) afirma que não é uma prática cooperativista comum, mas é desafiadora, interessante e as universidades deveriam testar, ou melhor, não poderiam prescindir dessa experiência. Além disso, Moureu (2020) estaca a falta de prioridades no tempo dentro das instituições de ensino para a dedicação de atividades importantes, como a implementação e gestão de cooperativas.

De forma complementar, destacamos como fator limitante ao desenvolvimento de uma Cooperativa Estudantil Universitária, pelo menos nas Universidades Estaduais baianas que ofertam os cursos de Agronomia, e em especial na UEFS, a quantidade de disciplinas que compõem o currículo, associada à sua pesada carga horária. O modelo curricular é extenso e absorve muito o estudante para as próprias disciplinas, não sobrando muito tempo para que ele possa vivenciar outras experiências acadêmicas mais relacionadas à extensão, à pesquisa e ao diálogo comunitário. Uma possível consequência é a ocorrência de algum grau de desarticulação entre teoria e prática.

\section{Oportunidades para implementação de uma cooperativa estudantil universitária}

Uma das primeiras oportunidades para implementação de uma cooperativa estudantil universitária é a falta dela ou o vácuo que a ausência dessa experiência representa para a formação acadêmica. Além disso, uma das razões para montar uma cooperativa em uma universidade é a necessidade de maior contato dos estudantes com as comunidades, com o campo dos negócios, das 
atividades comerciais, com as oportunidades de mercado, redes, feiras, arranjos produtivos locais, e porque não dizer, com os riscos inerentes aos negócios. Para tanto, é necessário projetar um plano de ação e executá-lo e, além disso, nortear esse plano, no intuito de tomar as decisões necessárias para sua implantação e condução. O plano deverá ser executado na própria universidade, onde os estudantes terão oportunidade de realizar atividades de gestão, além de vivenciar relações de trabalho, relações entre grupos e indivíduos, bem como exercitar práticas diversas.

Outra opção viável para o fortalecimento das iniciativas de trabalho cooperado é a abertura à participação dos servidores (técnicos ou docentes, guardadas as restrições legais pertinentes) da Universidade quando a legislação ou normas da cooperativa permitir que sejam integrados ao processo de trabalho cooperado, aumentando a complexidade das experiências, mas também contribuindo para a sua diversidade. Esses poderiam obter uma cota-parte e assim acessar os mesmos benefícios que os estudantes associados. Dessa forma, haveria maior disponibilidade de recursos/equipamentos o que, consequentemente, potencializaria os resultados das iniciativas.

Do ponto de vista institucional, um elemento relevante a ser considerado, em que pesem os aspectos burocráticos, é a credibilidade da Universidade Pública. Através dessas instituições as cooperativas podem promover cursos e capacitar agricultores familiares, envolvendo-se mais nas comunidades de forma política, educativa (diálogos, ensino, pesquisa e extensão) e com autonomia, sem abrir mão do compromisso com os direitos e garantias em relação a um ensino público, gratuito e de qualidade de acesso a todas e todos. Essas experiências podem ainda reforçar, junto às comunidades, a importância da organização e trabalho coletivo, e representar também um estímulo à formação de lideranças locais. Experiências de autogestão, especialmente as que envolvem a juventude, podem contribuir também para a ressignificação da vida no campo, combatendo o estigma de atraso e retrocesso ligado ao rural, e destacando as oportunidades de crescimento e desenvolvimento socioeconômico local - diferentes, mas não necessariamente piores do que aquelas acessíveis à juventude urbana.

Experiências de cooperativas também são muito importantes por possibilitar diversas práticas, tais como a organização de palestras, cursos, oficinas, rodas de conversas, organização documental, além da assistência técnica e fomentar a filosofia educativa cooperativista. Uma das prioridades que a Cooperativa Estudantil precisa ter, em especial, é o know-how, o poder da habilidade, da eficiência e da inovação na execução de determinados serviços ou tecnologias sociais, conforme discutem Rios e Lima (2019).

Nesse contexto, a criação de cooperativas pode contribuir também para o estabelecimento de redes de cooperação entre as Universidades Estaduais da Bahia (UEBAS), dado que o cooperativismo não vem tendo espaço nas grades curriculares dessas instituições - problemática particularmente sentida nos cursos de Agronomia. Além disso, no âmbito universitário, pode ser visto como uma outra 
oportunidade que vem a somar ou contrapor-se a elementos do modelo estabelecido de Empresa Júnior (CASTRO, 2020), visando, por meio do trabalho colaborativo, melhoria nas condições de educação (RUVER, 2018).

A Cooperativa Estudantil pode ser vista como uma grande experiência alternativa para os estudantes de Agronomia da Bahia, em especial para a UEFS que possui um currículo voltado à Agricultura Familiar e à Agroecologia (UEFS, 2010). Sendo assim, tal modelo deveria ser uma oportunidade para estabelecimento dos sistemas de base agroecológicas, firmando o grande diferencial que é a ênfase do curso no estado (CASTRO, 2020). Além disso, a instituição dispõe de uma vasta área ociosa no campus. Segundo Castro (2020), um estudo sobre o que é necessário como os limites territoriais e/ou os gastos e requisitos gerais para criação e implementação de uma cooperativa, está sendo realizado para pôr em prática projetos desenhados pelos colaboradores da unidade experimental Centro de Agroecologia Rio Seco (CEARIS) na UEFS.

\section{Considerações finais}

As Cooperativas, conforme seus princípios, limites e possibilidades, são relevantes tipologias alternativas que dialogam com uma outra economia, particularmente, economias plurais como a Economia Popular e Solidária, pois têm entre suas principais características a cooperação e a solidariedade e possuem fundamentos pautados na autogestão, democracia, autonomia e independência, caracterizando o modelo como fomentador de desenvolvimento social e econômico local, atendendo às sensibilidades negligenciadas pelo sistema capitalista ou por tipologias organizativas de capital convencional.

Com efeito, as Cooperativas Universitárias Estudantis são modelos derivados, adaptados ou aperfeiçoados às necessidades acadêmicas de produção e disseminação de conhecimento técnico, científico ou popular, visando otimizar as condições de ensino, pesquisa e extensão. Mesmo com alto grau de relevância, sua formação e desenvolvimento enfrentam entraves que variam desde a mobilização estudantil ao apoio da comunidade acadêmica, em especial na Bahia, onde não há nenhuma cooperativa estudantil universitária formalmente constituída.

Mesmo com tantas dificuldades, a perspectiva de organização de Cooperativas Estudantis apresenta-se como grande oportunidade para o desenvolvimento acadêmico, como forma alternativa de aprendizado. Trabalhos de mobilização, reconhecimento e incentivo devem ser realizados para a promoção de tal modelo, a fim de contribuir para o seu progresso no estado, a partir das experiências universitárias.

A relevância das Cooperativas Estudantis na formação profissional dos estudantes de Agronomia, recorte específico desta pesquisa, pôde ser percebida pelo entusiasmo provocado no processo de 
discussão deste trabalho na UEFS. No entanto, registramos também as dificuldades para sua implantação, relacionadas aos entraves culturais e burocráticos apresentados a partir da natureza de ser das universidades públicas, cuja dinâmica volta-se restritivamente para o empreendedorismo empresarial limite este, proporcional aos importantes desafios a serem vencidos.

Neste sentido, em que pesem os poucos estudos realizados nessa área, bem como a necessidade de ampliar tais discussões, acreditamos ter alcançado nosso objetivo, de apresentar e analisar as possibilidades de implantação de Cooperativas Estudantis Universitárias na Bahia, tendo como base os princípios e fundamentos do cooperativismo.

\section{Referências}

ARAGÃO, G. A.. O cooperativismo como base econômica para uma sociedade transformada. Bahia Análise e Dados, Salvador, v. 23, n. 1, pp. 9-21, Jan./ mar. 2013. Disponível em: http://www2.setre.ba.gov.br/arquivos/BA\&D v23 n1 web.pdf. Acesso em: 17 ago. 2020.

ARAÚJO, G. dos S.. Uma análise da dimensão educativa das cooperativas de crédito rural solidário no território do sisal - Bahia. 2016. 178 f. Dissertação (Mestrado) - Instituto de Políticas Públicas e Relações Internacionais, São Paulo, 2016. Disponível em: https://repositorio.unesp.br/handle/11449/144378. Acesso em: 17 ago. 2020.

BOCAYUVA, P. C.. Incubadora tecnológica de cooperativas populares Coppe/UFRJ. In: CAMAROTTI, I.; SPINK, P. Redução da pobreza e dinâmicas locais. 2. ed. Rio de Janeiro: FGV, 2002. pp. 235-263.

CANÇADO, A. C.; SOUZA, M. de F.; PEREIRA, J. R.. Os princípios cooperativistas e a identidade do movimento cooperativista em xeque. Revista de Gestão e Organizações Cooperativas, [s. 1.], v. 1, n. 2, pp. 51-62, Abr. 2014. Disponível em: https://periodicos.ufsm.br/rgc/article/view/16279. Acesso em: 17 ago. 2020.

CASTRO, Marina Siqueira de. Entrevista concedida a Maryelle Vanilla de Abreu Cerqueira em conversa informal. Feira de Santana, 19 mar. 2020.

CRUZ, Jucelho Dantas da. Entrevista concedida a Maryelle Vanilla de Abreu Cerqueira em conversa informal. Feira de Santana, 15 mar. 2020.

MOUREU, Mauricio Santana. Entrevista concedida a Fillipe Duarte Ribeiro via aplicativo de WhatsApp ®. Feira de Santana, 15 mar. 2020

PINHEIRO, M. A. H.. Cooperativas de Crédito História da evolução normativa no Brasil. Brasília, 2008.

REISDORFER, V. K.. Introdução ao cooperativismo. Santa Maria: Universidade Federal de Santa Maria, Colégio Politécnico, Rede e-Tec Brasil, 2014. 106 p. 
RIOS, D. M. da S.; LIMA, J. R. O.. O desenvolvimento local endógeno: reflexões a partir das tecnologias com foco na tecnologia social. Ambivalências, [s. 1.], v. 7, n. 14, pp. 125-142, jul./ Dez. 2019. Disponível em: https://tinyurl.com/y2r9ap5a. Acesso em: 17 ago. 2020.

RUVER, F. A.. Estratégias para o fomento do cooperativismo estudantil: uma proposta de plano de ação com base no mapeamento de experiências e na consulta a estudantes da UFFS Campus Chapecó. 2018. 101 f. Trabalho de Conclusão de Curso (Graduação) - Universidade Federal da Fronteira Sul, Chapecó, 2018.

RUVER, F. A.. Estratégias para o fomento do cooperativismo estudantil na UFFS campus Chapecó/SC. Revista Cadernos de Economia, v. 24, n. 40, pp. 1-24, 2020.

SANTOS, Gilberto Marcos de Mendonça. Entrevista concedida a Maryelle Vanilla de Abreu Cerqueira em conversa informal. Feira de Santana, 13 mar. 2020.

SINGER, P. et al. A Economia Solidária no Brasil: a autogestão como resposta ao desemprego. 2. ed. São Paulo: Contexto. 2003.

THIOLLENT, M.. Metodologia da pesquisa-ação. 18. ed. São Paulo: Cortez, 2011.

UEFS - UNIVERSIDADE ESTADUAL DE FEIRA DE SANTANA. Projeto Pedagógico do Curso de Agronomia. Feira de Santana, 2010. 77 p.

VEIGA, S. M.; FONSECA, I.. Cooperativismo: uma revolução pacífica em ação. Rio de Janeiro: DP\&A: Fase, 2002.

\begin{tabular}{|c|c|}
\hline Informações do Artigo & Article Information \\
\hline Recebido em: 22/09/2020 & Received on: 22/09/202 \\
\hline Aceito em: 09/04/2021 & Accepted in: 09/04/2021 \\
\hline Publicado em: 27/05/2021 & Published on: 27/05/2021 \\
\hline $\begin{array}{l}\text { Conflitos de Interesse: Os autores declaram não } \\
\text { haver quaisquer conflitos de interesse referente a } \\
\text { este artigo. }\end{array}$ & Conflict of Interest: No reported. \\
\hline Como citar este artigo & How to cite this article \\
\hline $\begin{array}{l}\text { Cerqueira, M. V. A. et al., (2021). Cooperativas } \\
\text { estudantis universitárias na Bahia: desafios e } \\
\text { oportunidades. Revista Macambira, 5(1), } \\
\text { e051004. https://doi.org/10.35642/rm.v5i1.486. }\end{array}$ & $\begin{array}{l}\text { Cerqueira, M. V. A. et al., (2021). University } \\
\text { student cooperatives in Bahia: challenges and } \\
\text { opportunities. Revista Macambira, 5(1), e051004. } \\
\text { https://doi.org/10.35642/rm.v5i1.486. }\end{array}$ \\
\hline Licença: & License: $\quad$ (c) \\
\hline $\begin{array}{l}\text { Este trabalho está licenciado sob uma Licença } \\
\text { Internacional Creative Commons Attribution- } \\
\text { NonCommercial-ShareAlike } 4.0 \text { International . }\end{array}$ & $\begin{array}{l}\text { This work is licensed under a Creative Commons } \\
\text { Attribution-NonCommercial-ShareAlike } \\
\text { International License. }\end{array}$ \\
\hline
\end{tabular}

